\title{
BIOGAMA - RECICLAGEM DE ÓLEO DE FRITURA E CONSCIENTIZAÇÃO AMBIENTAL A PARTIR DE COLETA SELETIVA NA COMUNIDADE DO GAMA - DF.
}

O Programa Biogama existe na Faculdade do Gama da Universidade de Brasília (FGA UnB) há oito anos e tem como principal objetivo promover o despertar na consciência da comunidade de Brasília com relação ao meio ambiente, a partir de um tema central: descarte incorreto de óleos residuais de cozinha.

As professoras Patricia Sobral Braga, Andreia Costa e Roseany V Lopes são responsáveis pela condução do Projeto Biogama na Universidade de Brasília-UnB.

Ao tratar deste problema, o Programa BIOGAMA visa promover a interação entre a Universidade e a comunidade geral por meio de ações integradas com a sociedade, envolvendo conceitos ligados diretamente às disciplinas do curso de Engenharia de Energia, principalmente Química Geral; Engenharia e Ambiente e Combustíveis e Biocombustíveis.

\section{Dentro de qual contexto surge o Programa Biogama?}

O Programa BIOGAMA surgiu da necessidade de se resolver um problema vivenciado por um aluno do curso de Engenharia de Energia. Esse problema estava relacionado à grande quantidade de óleo residual obtido pelo seu pai em seu estabelecimento comercial. Assim, em 2009, foi criado o Projeto Biogama, que mais tarde, se transformaria no Programa BIOGAMA, capaz de atender aos três campi da Universidade de Brasília: FGA (Campus Gama), FUP (Campus Planaltina) e Darcy Ribeiro (Campus Asa Norte).

A partir dessa ideia, a prof ${ }^{a}$ Grace Ferreira Ghesti e o aluno Lucas Machado Gaio começaram a implementar a coleta de óleo residual nos estabelecimentos do Gama e do Entorno do Distrito Federal, a fim transformar o óleo usado em produtos com maior valor agregado. Assim, houve a formalização do Projeto Biogama no sistema de extensão da Universidade de Brasília (Decanato de Extensão - DEX).

Com o passar dos anos, a equipe do Projeto resolveu ampliar as atividades desenvolvidas e então o BIOGAMA se transformou em Programa institucional. Desde 2013, o Programa atua com atividades em três dos quatro Campi da UnB e possui oito professores responsáveis e mais de trinta alunos de graduação em seu grupo de trabalho.

A metodologia empregada para se alcançar os objetivos do Programa BIOGAMA está baseada na interlocução entre os discentes e docentes da UnB com a população, a partir 
das atividades de apresentações e oficinas em escolas públicas e privadas bem como em eventos científicos e na Universidade. Além disso, também existem visitas à

Universidade. Os alunos também realizam a fabricação de material de marketing, criação de site próprio e a preparação e a apresentação de produtos de alto valor agregado para a sociedade.

\section{Qual o perfil dos participantes e escolas atendidas ate o momento?}

O perfil do estudante que participa do Programa está relacionado ao interesse do aluno em atividades de extensão, não necessariamente alunos de graduação do curso de Engenharia de Energia. Os professores realizam uma entrevista inicial com o estudante, solicitando que participem das atividades conforme as demandas do Programa.

O foco do Programa BIOGAMA é bastante variado, se destacando as atividades realizadas nas Escolas de Ensinos Fundamental e Médio como feira de ciências ou feiras de profissões bem como nas apresentações dentro da Universidade e/ou Órgãos Públicos. Assim, os conteúdos interdisciplinares são trabalhados diretamente nas palestras e oficinas, com uma linguagem simples e de fácil acesso para os ouvintes. A Figura 1 apresenta alguns combustíveis além das amostras de óleo vegetal (usado e puro), exibidos no estande do Programa BIOGAMA, durante uma apresentação do grupo na Semana Nacional de Ciência e Tecnologia de 2015.

Figura 1. (a) Programa BIOGAMA na Semana Nacional de Ciência e Tecnologia; (b) da esquerda para a direita, amostras no estande Biogama: diesel, biodiesel, óleo residual de fritura, óleo vegetal puro, álcool, gasolina aditivada e gasolina comum.

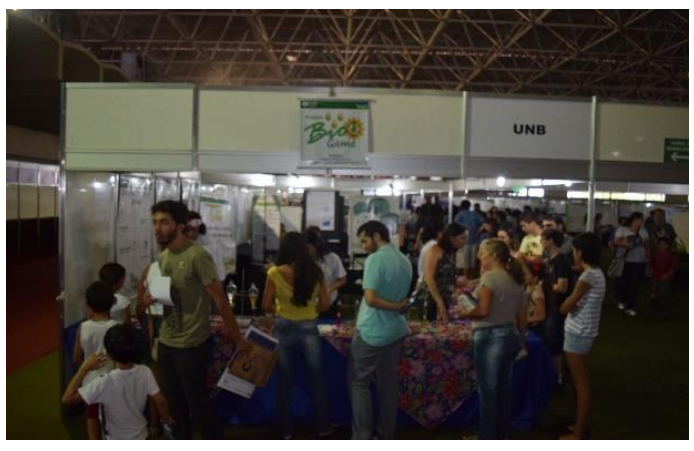

(a)

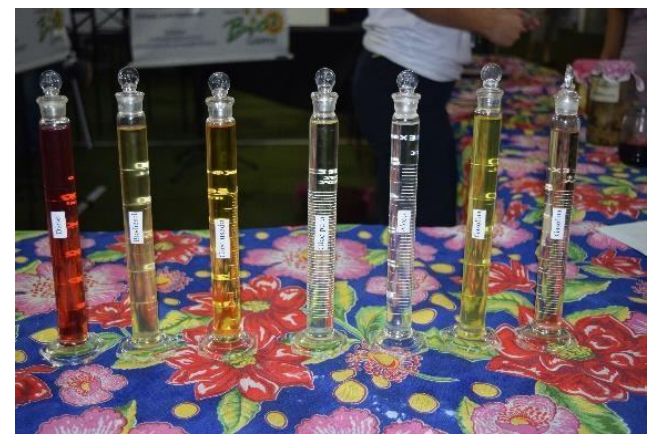

(b)

\section{De que maneira o Programa BIOGAMA pode, em longo prazo, despertar as pessoas para a importância de reutilização do óleo de cozinha?}

O Programa BIOGAMA pode reconstruir o pensamento da comunidade para a forma correta de descarte e transformação do óleo residual de cozinha. Para isso, as oficinas de preparo de sabão é uma das atividades realizadas, com a distribuição de panfletos 
educativos (Figura 2) e sabão para limpeza pesada e não para uso em higienização pessoal.

Figura 2. Panfletos produzidos pelo Programa BIOGAMA para distribuição em palestras.

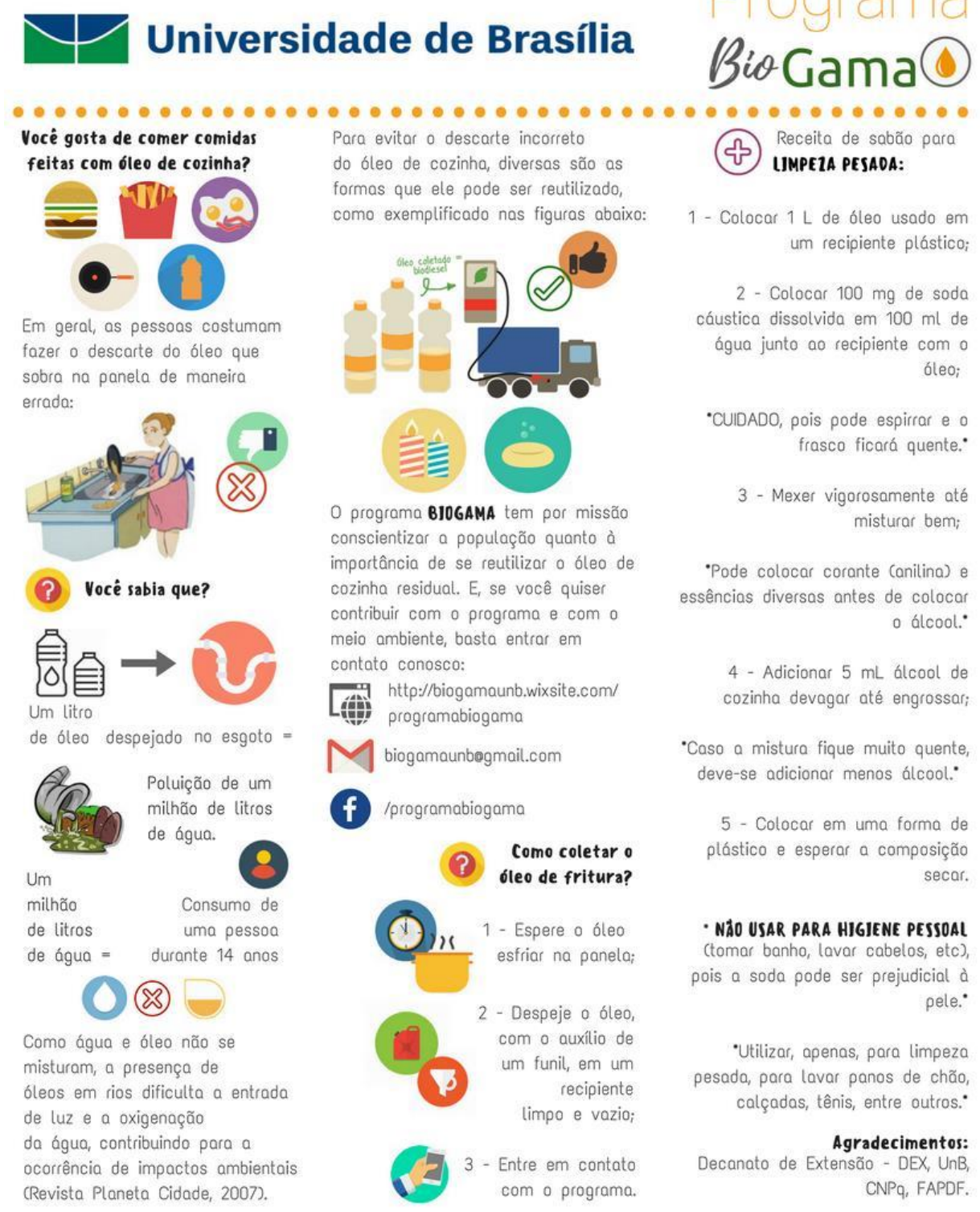

\section{Quais são efetivamente os principais danos causados pelo descarte errado e inadequado do óleo de cozinha? De que maneira esses subprodutos poderiam ser comercializados?}

Esse resíduo, gerado diariamente pela população em domicílios e/ou estabelecimentos comerciais e industriais, quando despejado diretamente nas redes de esgoto dos sistemas urbanos, geram grandes danos ao meio aquático, contribuindo para o desequilíbrio em 
ambientes aquáticos causando morte de fauna e de flora. Além disso, podem contribuir para o entupimento dos canos e para o encarecimento dos processos das estações de tratamento.

Os principais produtos que podem ser obtidos da transformação do óleo usado estão mostrados no fluxograma da Figura 3, além da confecção de velas. A produção de biodiesel pode produzir um biocombustível renovável assim como a produção de sabão para a limpeza pesada, os quais são os produtos mais interessantes para o Programa.

Figura 3. Principais produtos produzidos pela transformação do óleo residual.

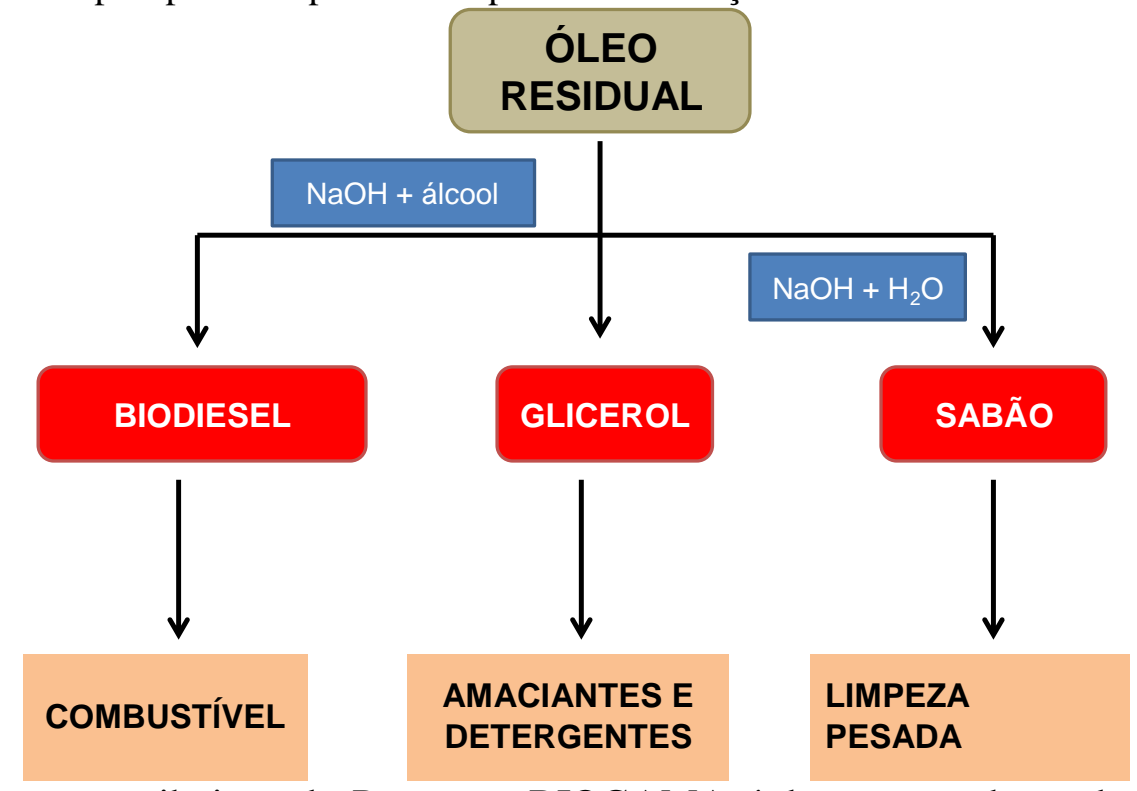

Uma valiosa contribuição do Programa BIOGAMA é demonstrar de modo sustentável que a obtenção destes produtos se mostra como uma forte ferramenta para inclusão social e geração de renda, acompanhado de um aumento no desenvolvimento da consciência ambiental da comunidade do Gama e Entorno do Distrito Federal.

\section{Quais são as ações futuras prevista no Programa?}

O Programa está sempre realizando atividades de Palestras e Oficinas de Sabão. Assim, como ações futuras são novas participações em escolas de Ensinos Fundamental e Médio bem como eventos de interesse nacional.

\section{De que forma, professores, discentes e outros participantes poderão aderir ao Programa?}

A adesão ao Programa ocorre sempre no início do semestre letivo da UnB com uma entrevista com os alunos de graduação interessados. Basta o estudante procurar por mim para que possamos realizar a entrevista e efetivar a participação no Programa. 